\section{Factors affecting visual outcomes in patients with diabetic macular edema treated with ranibizumab}

R Channa' ${ }^{1}$, R Sophie ${ }^{1}$, AA Khwaja', DV Do ${ }^{1,3}$, G Hafiz $^{1}$, QD Nguyen ${ }^{1,3}$, PA Campochiaro ${ }^{1}$ and the READ-2 Study Group ${ }^{2}$

\begin{abstract}
Purpose To identify factors associated with visual outcomes in patients with diabetic macular edema (DME) treated with ranibizumab (RBZ) in the Ranibizumab for Edema of the mAcula in Diabetes-Protocol 2 (READ-2) Study.

Patients and methods Optical coherence tomography scans, fundus photographs, and fluorescein angiograms (FAs) were graded and along with baseline characteristics were correlated with month (M) 24 visual outcome of best-corrected visual acuity (BCVA) $\leq 20 / 100$ (poor outcome) $v s>20 / 100$ (better outcome). Results Of 101 patients with a M20 visit or beyond, $27(27 \%)$ had BCVA $\leq 20 / 100$. Comparison of patients with or without poor outcome showed mean baseline BCVA of 16.8 letters (20/125) in the former compared with 30.4 letters $(20 / 63 ; P<0.001)$. Mean change in BCVA between baseline and M24 was - 2.6 letters in the poor outcome group compared with +9.8 letters $(P<0.001)$. Foveal thickness (FTH) at M24 was $374.1 \mu \mathrm{m}$ in the poor outcome group compared with $268.8 \mu \mathrm{m}$ $(P<0.01)$, a difference driven by 14 patients with mean FTH of $450.3 \mu \mathrm{m}$. Foveal atrophy occurred in $65 \%(11 / 17)$ in the poor outcome group compared with $17 \%(12 / 71, P=0.001)$. Persistent edema was noted in $52 \%(14 / 27)$ of patients with poor outcome. Laser scars near foveal center were significantly more common in patients with poor outcome who did not have edema $v s$ those who did (78\% (7/9) vs $23 \%$ (3/13) $P=0.03$ ).

Conclusion Poor baseline BCVA $(\leq 20 / 125)$ in DME patients predicts poor visual outcome $(\leq 20 / 100)$ after 2 years of treatment with RBZ and/or focal/grid laser, often due to foveal atrophy and/or persistent edema.
\end{abstract}

Eye (2014) 28, 269-278; doi:10.1038/eye.2013.245; published online 22 November 2013

Keywords: macular edema; diabetic macular edema; ranibizumab; anti-VEGF

\section{Introduction}

Diabetic retinopathy is a prevalent cause of reduced vision, mostly due to diabetic macular edema (DME). ${ }^{1}$ Although the pathogenesis of DME is not completely understood, recent studies have demonstrated that vascular endothelial growth factor (VEGF) has a major role. ${ }^{2,3}$ The first study to clearly implicate VEGF was the Ranibizumab for Edema of the mAcula in Diabetes (READ) trial, which demonstrated a mean improvement in best-corrected visual acuity (BCVA) of 12.3 letters in patients with chronic DME given five intraocular injections of $0.5 \mathrm{mg}$ of ranibizumab (RBZ) over the course of 7 months. ${ }^{2}$ This led to the READ-2 study, in which patients with DME were randomized to receive intraocular injections of RBZ (RBZ group), focal/grid laser (laser group), or a combination of RBZ and focal/grid laser (RBZ + laser group). At the month (M) 6 primary end point, RBZ patients who were treated with intraocular injections of $0.5 \mathrm{mg}$ of RBZ at baseline and months 1, 3, and 5 showed a mean improvement in BCVA of 7.2 letters compared with -0.4 letters in the laser group $(P=0.01)$, whereas RBZ + laser patients had a mean improvement of 3.8 letters $(P=0.08) .^{3}$ After the primary end point, patients in the RBZ group were seen every 2 months and if foveal thickness (FTH, center subfield thickness) was $250 \mu \mathrm{m}$ or greater, with time domain optical coherence tomography (OCT), they were treated
${ }^{1}$ The Wilmer Eye Institute, Johns Hopkins University School of Medicine, Baltimore, MD, USA

${ }^{2}$ Members of the READ-2 Study Group are listed at the end of the article

Correspondence: PA Campochiaro, The Wilmer Eye Institute, Johns Hopkins University School of Medicine, Maumenee $719,600 \mathrm{~N}$. Wolfe Street, Baltimore, MD 21287-9277, USA

Tel: +1 410955 5106; Fax: +1 4106149315

E-mail: pcampo@jhmi.edu

${ }^{3}$ New address: Stanley M. Truhlsen Eye Institute, University of Nebraska Medical Center, Omaha, Nebraska

Received: 6 June 2013 Accepted in revised form: 8 October 2013 Published online: 22 November 2013 
with $0.5 \mathrm{mg}$ RBZ. Patients in the laser group were seen every 2 months and if FTH was $250 \mu$ m or greater, they could be treated with laser or RBZ. Patients in $\mathrm{RBZ}+$ laser group were seen every 3 months and if FTH was $250 \mu$ m or greater, they could receive laser plus RBZ or RBZ alone. At M24, the mean improvement in BCVA letters was 7.7, 5.1, and 6.8 in RBZ, laser, and RBZ + laser groups. ${ }^{4}$ Some patients had an outstanding outcome, with 45,44 , and $35 \%$ of patients having a M24 BCVA $\geq 20 / 40$, whereas others fared less well. In this study, we sought to determine why some patients in the READ-2 study had a suboptimal visual outcome.

\section{Materials and methods}

The design and protocol of the READ-2 study have been described in detail elsewhere ${ }^{3,4}$ and are summarized here. After the primary end point at M6, patients and investigators had the option to switch to RBZ only treatment. Consequently, during the 18-month follow-up period, patients in all three groups were mostly treated with RBZ alone. Patients were divided based upon visual outcome at M24 into poor visual outcome $(\leq 20 / 100)$ vs better visual outcome $(>20 / 100)$. Patients in the poor visual outcome group were further divided into two groups based on presence (poor vision/edema) or absence (poor vision/no edema) of edema contributing to poor BCVA. Edema was judged to be contributing to poor vision if there was foveal thickening at M24, and during months 12-24 there was a correlation between reduced FTH and improved BCVA. Patients were included in the analysis if they had completed 20-24 months of the READ-2 study, and M24 data were used when available. If a patient did not have the M24 study visit, but had a study visit at M20 or beyond, the last observation was carried forward. If fundus photography and fluorescein angiography (FA) images from M24 were not available, images from M12 were used for analysis as long as no laser treatment was administered between months 12 and 24. Data regarding demographics, baseline characteristics, BCVA, presence of edema, FTH, treatment received during the study, and grading of fundus photographs and FA images were analyzed and compared among groups. Fundus photography and FAs were analyzed at the Wilmer Retinal Imaging Research and Reading Center (RIRRC) for the presence of the following characteristics: evidence of extensive laser treatment, foveal atrophy, laser within $1 \mathrm{~mm}$ of the fovea, pigment changes within $1 \mathrm{~mm}$ of the fovea, and severe macular ischemia. Information regarding duration of macular edema was obtained from patient charts in which macular edema was first documented as a finding on exam or ophthalmic imaging. FTH of the central $1 \mathrm{~mm}$ of the macula was measured using Stratus Optical
Coherence Tomography, scans were reviewed at the RIRRC and the thickness values were used for analysis. Images were received electronically from all sites via a central database. Images acquired from different cameras were resized to have uniform dimensions across images, an ETDRS grid was overlaid, the area of the macula covered by laser scars was measured using the software Image J (National Institutes of Health, Bethesda, MD, USA; available at http:/ /rsbweb.nih.gov) and expressed as a percentage of the total area covered by the ETDRS grid. Patients were considered to have evidence of extensive laser treatment if more than $20 \%$ of the macula had laser scars or if patients had a history of having received laser treatment with more than 200 burns before being enrolled in the study. Laser scars were further assessed to look for presence in the central $1 \mathrm{~mm}$ of the ETDRS grid to determine whether laser treatment closer to the fovea was associated with poor visual outcomes. Severe macular ischemia was considered to be present if there was closure of perifoveal capillaries for $360^{\circ}$ extending at least $1 \mathrm{~mm}$ from the fovea. Foveal atrophy was judged from the presence of window defect on FA and retinal thinning on OCT images. If hyper- or hypopigmentary changes were identified on color FP in the central $1 \mathrm{~mm}$ of the macula, the patient was judged to have pigmentary changes.

Statistical Package for the Social Sciences version 19 (SPSS Inc., Chicago, IL, USA) was used for statistical analysis. For the purposes of analysis, fundus photo and FA characteristics that could not be graded were considered as missing values. The independent samples $t$-test was used for parametric variables, and the Wilcoxon Signed-Rank test was used for non-parametric variables. Differences in proportion among categorical variables were determined using Pearson's $\chi^{2}$ and Fisher's exact test. Variables that had a $P$-value of $<0.05$ upon univariate analysis were selected for the multivariate model. We certify that all applicable institutional and governmental regulations concerning the ethical use of human volunteers were followed during this research.

\section{Results}

The M24 disposition, visual outcome, and anatomic outcome of patients in the READ-2 study have been previously published. ${ }^{4}$ Of the 126 patients originally enrolled in the study, 101 had a study visit at M20 or beyond and are included in the analysis. Two patients had reduced vision at M24 owing to disease processes unrelated to DME or its treatment: one had vitreous hemorrhage and the other had a retinal vein occlusion. Fundus photographs and FAs were available for 95 of the remaining 99 patients and were analyzed. 
At M24, 27 (27\%) had BCVA $\leq 20 / 100$ and were classified as having poor visual outcome. Of the patients who had a better visual outcome, $42(57 \%)$ had $\mathrm{BCVA} \geq 20 / 40$. The characteristics of patients with a poor visual outcome were compared with those of the $74(73 \%)$ patients who had a better visual outcome.

\section{Effect of baseline characteristics and original treatment assignment on visual outcome}

The baseline characteristics of the groups are shown in Table 1. There were no significant differences in duration of DME, age, or race. The percentage of female patients was greater $(P=0.03$ by univariate analysis) in the poor visual outcome (59\%) vs the better outcome group (35\%). The mean BCVA at baseline was 16.8 letters (20/125) in the poor outcome group vs 30.4 letters $(20 / 63)$ in the better outcome group $(P<0.001$ by univariate and 0.001 by multivariate analyses).

The major differences in treatment occurred in the first 6 months of the trial and at the M6 primary end point, improvement from baseline BCVA was significantly greater in the RBZ group compared with the focal/grid laser group. ${ }^{3}$ After M6, RBZ was available to all patients as frequently as every 2 months if FTH was $250 \mu \mathrm{m}$ or greater, and at M24 there was no longer any difference in visual outcome among the three treatment groups. ${ }^{4}$

\section{Effect of treatment on visual outcome and course throughout trial}

The mean number of RBZ injections through M24 (6.9 vs $5.9, P=0.27$ ) and the mean number of focal/grid laser treatments administered before and during the study (3.0 vs $2.7, P=0.59$ ) were not significantly different in the poor $v$ s better outcome group (Table 2). The peak BCVA recorded for all study visits provides an assessment of visual potential. The mean peak BCVA was 28.4 letters $(20 / 63)$ in poor visual outcome group vs 44 letters $(20 / 32)$ in the better outcome group $(P<0.001)$. The difference between baseline and peak BCVA was not significantly different in the poor (11.7 letters) vs better outcome group $13.6(P=0.28)$. Patients in the poor visual outcome group did not maintain BCVA at peak and on average lost 2.6 letters compared with a gain of 9.8 letters in the better outcome group $(P<0.001)$. The average time point in the study at which maximum improvement in VA occurred was significantly earlier in the poor $v$ s the better visual outcome group (12 vs 17 months; $P=0.002$ ).

Table 1 Baseline characteristics of patients in the study

\begin{tabular}{lccc}
\hline Patient characteristics & Poor outcome $(\mathrm{n}=27)$ & Better outcome $(\mathrm{n}=74)$ & P-value \\
\hline Gender (\% women) $^{\mathrm{a}}$ & $16(59)$ & $26(35)$ & 0.03 \\
Race (\% Caucasian) & $19(70)$ & $52(70)$ & 62.4 \\
Mean age (years) & 64.9 & 23.6 & 0.44 \\
Duration of DME (mos) & 32.3 & $30.4(20 / 63)$ & 0.19 \\
Mean BCVA in ETDRS letters (Snellen) $^{\mathrm{a}}$ & $16.8(20 / 125)$ & 427.0 & 0.29 \\
Mean foveal thickness $(\mu \mathrm{m})$ & 496.6 & $25(34)$ & 0.001 \\
Patients randomized to ranibizumab group (\%) & $8(30)$ & $24(32)$ & 0.79 \\
Patients randomized to laser group (\%) & $10(37)$ & $25(34)$ & 0.67 \\
Patients randomized to ranibizumab +laser group $(\%)$ & $9(33)$ & 0.97 \\
\hline
\end{tabular}

Abbreviations: BCVA, best-corrected visual acuity; ETDRS, early treatment diabetic retinopathy study; mos, months.

a Significant with $P<0.05$ on univariate analysis.

Table 2 Vision and anatomic outcomes and treatments administered

\begin{tabular}{|c|c|c|c|}
\hline Outcomes and treatments & Poor outcome $(\mathrm{n}=27)$ & Better outcome $(\mathrm{n}=74)$ & P-value \\
\hline Mean number of RBZ injections over 24 mos & 6.9 & 5.9 & 0.27 \\
\hline Mean number of focal laser treatments before and during study & 3.0 & 2.7 & 0.59 \\
\hline Mean peak $\mathrm{VA}^{\mathrm{a}}$ & $28.4(20 / 63)$ & $44.0(20 / 32)$ & $<0.001$ \\
\hline Mean change in VA from baseline to peak & 11.7 & 13.6 & 0.28 \\
\hline Time from baseline to peak $\mathrm{VA}^{\mathrm{a}}$ & 12.0 & 17.0 & 0.002 \\
\hline Mean change in VA from baseline to M24 ${ }^{\mathrm{a}}$ & -2.6 & 9.8 & $<0.001$ \\
\hline Mean VA M24 & $14.1(20 / 125)$ & $40.0(20 / 40)$ & $<0.001$ \\
\hline FTH at M24 $(\mu \mathrm{m})^{\mathrm{a}}$ & 374.1 & 268.8 & 0.005 \\
\hline Patients who had cataract progression (\%) & $3(11.1)$ & $10(13.5)$ & 1.0 \\
\hline Patients who had cataract surgery (\%) & $1(3.7)$ & $4(5.4)$ & 1.0 \\
\hline
\end{tabular}

Abbreviations: BCVA, best-corrected visual acuity; M, month; mos, months.

a Significant with $P<0.05$ on univariate analysis. 
Mean FTH at M24 was $374.1 \mu \mathrm{m}$ in the poor visual outcome group $v$ s $268.8 \mu \mathrm{m}$ in the better outcome group ( $P=0.005$ by univariate and $P=0.01$ by multivariate analysis; Table 2).

\section{Effect of cataract surgery or cataract progression on visual outcome}

Between baseline and M24, 1 of 27 patients in the poor outcome group and $4 / 74$ in the better outcome group underwent cataract surgery, and $3 / 27$ patients in the poor outcome group and 10/74 in the better outcome group had progression of cataract that was not severe enough to consider cataract surgery. Neither of these differences was statistically significant (Table 2).

\section{Differences in fluorescein angiographic and treatment characteristics between groups}

Of the 95 sets of color and FA images available for analysis, the following could not be graded: two images for the presence of laser scars in the central $1 \mathrm{~mm}$, seven for foveal atrophy, one for pigmentary changes in the fovea, and nine for the presence of severe macular ischemia. Table 3 summarizes the color photographic and FA characteristics between the groups. Foveal atrophy

Table 3 Characteristics identified on fluorescein angiogram

\begin{tabular}{|c|c|c|c|}
\hline $\begin{array}{l}\text { Fluorescein } \\
\text { angiographic } \\
\text { characteristics }\end{array}$ & $\begin{array}{l}\text { Poor outcome } \\
\%(n / n \text { graded })\end{array}$ & $\begin{array}{l}\text { Better outcome } \\
\%(n / n \text { graded })\end{array}$ & P-value \\
\hline Foveal atrophy ${ }^{\mathrm{a}}$ & $65(11 / 17)$ & $17(12 / 71)$ & $<0.001$ \\
\hline $\begin{array}{l}\text { Pigmentary changes } \\
\text { in the fovea }\end{array}$ & $70(16 / 23)$ & $39(28 / 71)$ & 0.01 \\
\hline Extensive laser & $58(14 / 24)$ & $45(32 / 71)$ & 0.26 \\
\hline Laser in central $1 \mathrm{~mm}$ & $46(10 / 22)$ & $52(37 / 71)$ & 0.59 \\
\hline $\begin{array}{l}\text { Severe macular } \\
\text { ischemia }\end{array}$ & $21(4 / 19)$ & $10(7 / 67)$ & 0.25 \\
\hline
\end{tabular}

${ }^{a}$ Significant with $P<0.05$ on univariate analysis.

Table 4 Multivariate analysis of factors associated with poor visual outcomes in the READ-2 study

\begin{tabular}{lccc}
\hline Variables & Odds ratio & $95 \% \mathrm{CI}$ & P-value \\
\hline BCVA at BL $^{\mathrm{a}}$ & 0.83 & $0.75-0.93$ & 0.001 \\
Male gender $^{\text {FTH at M24 }}$ & 0.75 & $0.17-3.3$ & 0.70 \\
Foveal atrophy $^{\mathrm{a}}$ & 1.008 & $1.002-1.013$ & 0.01 \\
Pigmentary changes $_{\text {in the fovea }}$ & 0.42 .3 & $1.8-117.1$ & 0.01 \\
& & $0.5-3.3$ & 0.41 \\
\end{tabular}

Abbreviations: BCVA, best-corrected visual acuity; $\mathrm{BL}$, baseline; FTH, foveal thickness; $M$, month.

${ }^{a}$ Significant with $P<0.05$ on multivariate analysis. was identified in $65 \%(11 / 17)$ in the poor outcome group and $17 \%(12 / 71)$ in the better outcome group $(P<0.001$ by univariate and $P=0.01$ by multivariate analysis, Table 4). Pigmentary changes in the fovea were more frequent in patients in the poor outcome vs better outcome groups (70 vs 39\%, $P=0.01$ ); however, this difference was not significant by multivariate analysis. Extensive macular laser treatment and laser within the central $1 \mathrm{~mm}$ were almost equivalent among groups: $58 \%$ $(14 / 24)$ and $46 \%(10 / 22)$ in poor visual outcome vs $45 \%$ $(32 / 71)$ and $52 \%(37 / 71)$ in the better outcome groups $(P=0.26$ and $P=0.59)$. Severe macular ischemia was present in 4 of $17(21 \%)$ in the poor visual outcome group and 7 of $67(10 \%)$ in the better outcome group $(P=0.25)$.

\section{Further analysis of patients with poor VA outcome}

Among the 27 patients in the poor visual outcome group, edema could not be ruled out as a cause of poor VA in 14, although 13 patients had little or no edema. Figure 1 shows images from a patient in which persistent/ recurrent edema contributed to poor visual outcome, and Figure 2 shows images from a patient who had a poor visual outcome despite the absence of edema. Table 5 summarizes differences in characteristics between the two groups. There were no significant differences in gender, race, age, duration of disease, BCVA, or FTH at baseline. There was a higher percentage of patients in the RBZ group (50\% (7/14) vs 7\% (1/13), $P=0.03)$ and a lower percentage in the RBZ + laser group $(14 \%(2 / 14)$ vs $54 \%(7 / 13), P=0.04)$ who had edema at the M24 visit. The mean times to peak BCVA and the magnitude of peak BCVA gain were similar between groups (10.2 vs 13.6, $P=0.2 ; 15.0$ vs $8.1, P=0.35)$. However, patients in the edema group maintained BCVA between baseline and M24, whereas patients in the edema-free group lost on average 5.9 letters between baseline and M24. Patients with edema required a significantly higher number of injections (9.2 vs 4.3,P<0.001), and FTH at M24 was higher $(450.3 \mu \mathrm{m}$ vs $292.2 \mu \mathrm{m}, P=0.004)$. The percentage of patients who received extensive laser treatments as well as total number of laser treatments was similar between groups $(46 \%(6 / 13)$ vs $73 \%(8 / 11), P=0.24$; 2.5 vs $3.4, P=0.29$ ). However, laser in the central $1 \mathrm{~mm}$ was significantly more frequent in the edema-free group (78\% (7/9) vs 23\% (3/13), $P=0.03)$. Owing to the small numbers, this sub-analysis was not adjusted for possible confounding variables.

\section{Discussion}

Several studies have demonstrated that VEGF antagonists provide benefit in patients with DME. ${ }^{3-8}$ These studies show that on average patients with DME 


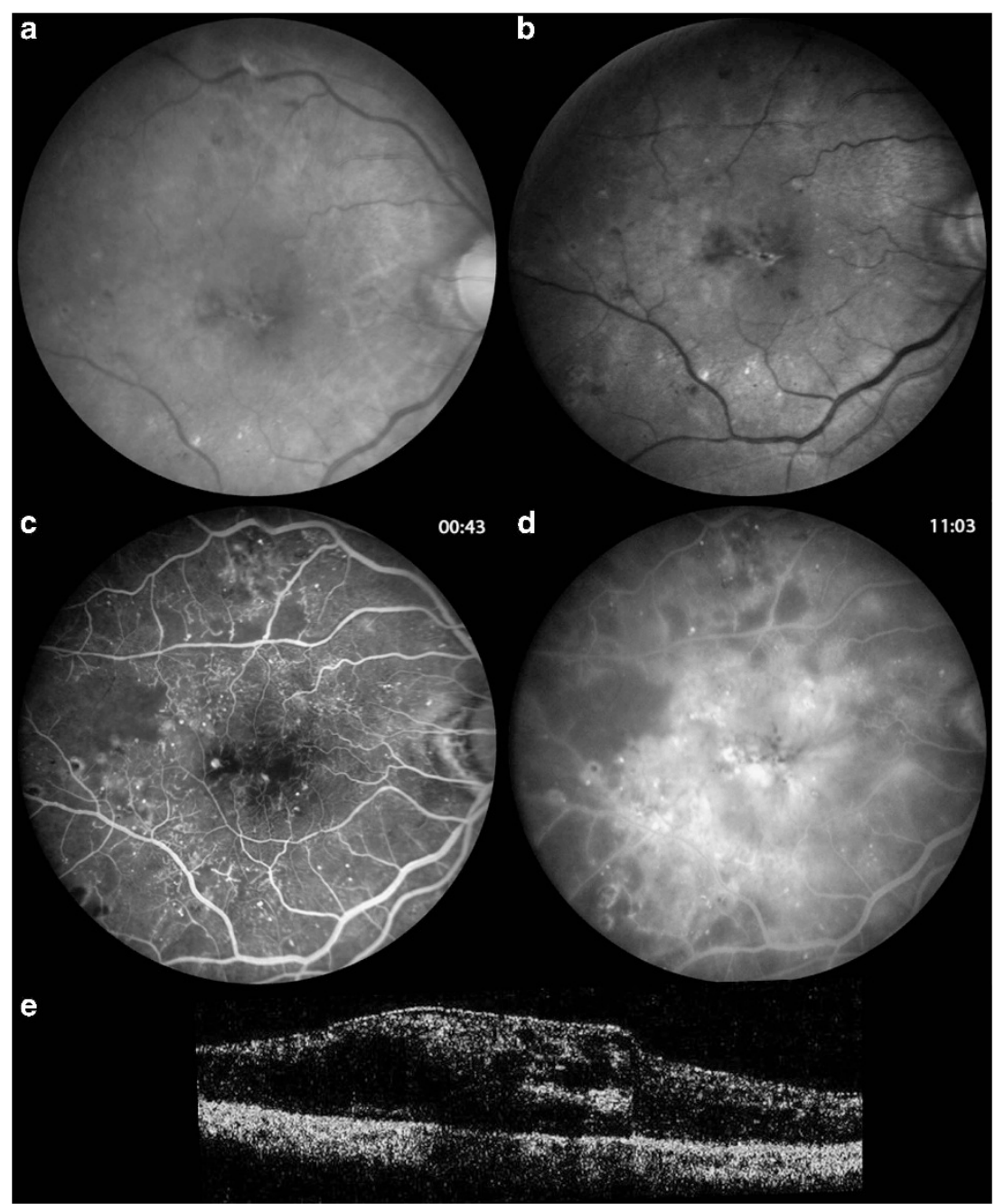

Figure 1 Images at M24 of a patient with poor visual outcome in which recurrent macular edema contributed. Fundus photograph (a) and red-free photograph (b) show some pigmentary changes adjacent to the fovea, laser burns temporally, exudates inferiorly, and a few hemorrhages and microaneurysms. An early frame of a FA taken $43 \mathrm{~s}$ after dye injection (c) shows many microaneurysms and areas of capillary closure temporally and superiorly. A late frame of the FA taken $11 \mathrm{~min}$ and $3 \mathrm{~s}$ after dye injection (d) shows severe leakage with pooling of dye in the fovea in a petaloid pattern. A horizontal time domain OCT scan through the fovea (e) shows severe thickening and intraretinal fluid.

experience reduction in retinal thickness and improvement in BCVA when treated with an anti-VEGF agent or with a combination of an anti-VEGF agent and focal/grid laser. However, although some patients improve to near-normal levels, others are left with substantial visual disability. In this study, we sought to determine why visual outcomes vary in patients with DME treated with RBZ. As the range of visual outcomes is large and the differences among patients are large, this sort of analysis is very complex. To reduce complexity, we performed a categorical analysis. Given new criteria for legal blindness when using ETDRS charts (http:/ / www.lighthouse.org/about-low-vision-blindness / definition-legal-blindness/), patients with BCVA of 20/100 or worse were considered to have a poor visual outcome.
Compared with patients who had a better visual outcome, those with a poor outcome had a significantly lower mean baseline BCVA. These two groups showed almost an equal peak improvement, but the change from baseline to M24 was - 2.6 letters in the poor outcome group compared with +9.8 letters in the better outcome group. This suggests that both groups had potential for visual gain, but it was only achieved in one of them. Uncontrolled edema accounted for poor visual outcome in about half the patients in the poor visual outcome group and these patients could still have some improvement in vision with better control of edema. In fact, after M24, the protocol was amended and patients were evaluated every month and recurrent or persistent edema was treated with RBZ; this resulted in reduced 


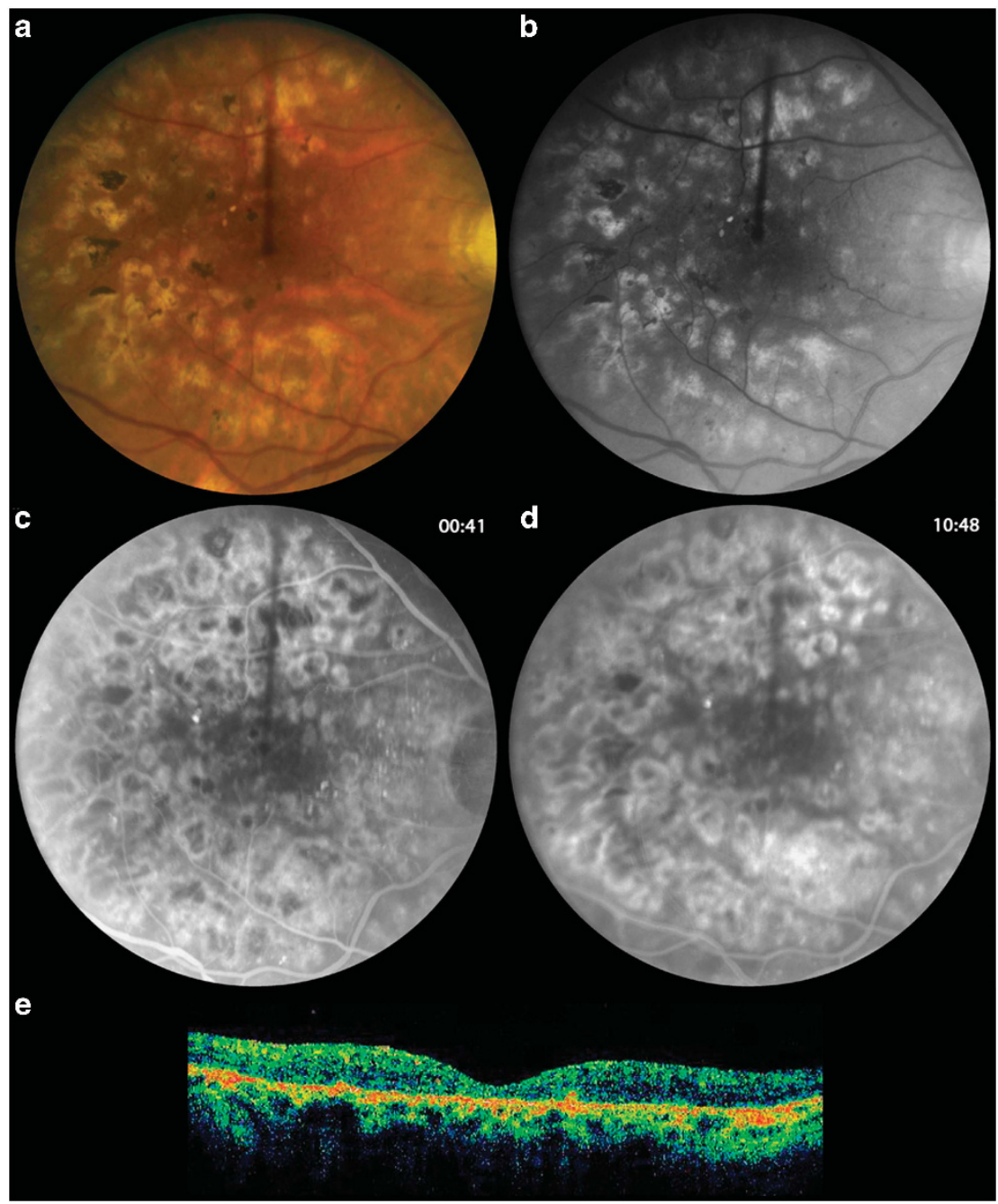

Figure 2 Images at M24 of a patient with poor visual outcome in which recurrent macular edema did not contribute. Fundus photograph (a) and red-free photograph (b) show some numerous laser scars surrounding the fovea (within $1 \mathrm{~mm}$ ) and throughout the posterior pole. An early frame of a fluorescein angiogram (FA) taken $41 \mathrm{~s}$ after dye injection (c) shows hyper- and hypofluorescent spots in areas of laser burns and pigmentary changes and some microaneurysms between the disc and fovea. A late frame of the FA taken $10 \mathrm{~min}$ and $48 \mathrm{~s}$ after dye injection (d) shows mild leakage associated with the microaneursyms near the disc, but no leakage or pooling of dye near the fovea. A horizontal time domain optical coherence tomography scan through the fovea (e) shows no thickening or intraretinal fluid.

FTH and visual improvement in many of the patients who had residual edema at $\mathrm{M} 24 .{ }^{9}$ In the remaining half of the patients with poor visual outcome, there was no residual edema contributing to reduced vision.

In patients with poor visual outcome, foveal atrophy was significantly more frequent than in patients with better outcome. This suggests that photoreceptor damage is a major contributor to poor visual outcome. There are several possible causes for photoreceptor damage, including chronicity of edema, ischemia, or foveal damage from photocoagulation. Although this study has not provided definitive evidence that long-standing persistent and/or recurrent edema contributed to poor outcome, there are some hints that this may be the case.
Poor vision at baseline correlated with a poor visual outcome and patients with more severe edema had poor vision at baseline. Patients with poor baseline vision still had some potential for visual improvement, because many of them showed substantial improvement from baseline BCVA at some point in the trial, but this improvement was gradually lost. Whether this loss could have been prevented by better control of edema is an important question that should be investigated in the future.

Macular ischemia has been suggested to be associated with poor visual outcomes in patients with DME. 10,11 We did not find a significant association between severe macular ischemia and poor visual outcome regardless of 
Table 5 Comparison of factors among poor vision groups

\begin{tabular}{|c|c|c|c|}
\hline Variables & $\begin{array}{c}\text { Poor vision; edema } \\
\text { contributory group } 1 A \\
(\mathrm{n}=14)\end{array}$ & $\begin{array}{l}\text { Poor vision; edema } \\
\text { not contributory group } 1 B \\
\qquad(\mathrm{n}=13)\end{array}$ & P-value \\
\hline \multicolumn{4}{|l|}{ Baseline characteristics } \\
\hline Gender (\% women) & $6(43)$ & $10(77)$ & 0.12 \\
\hline Race (\% Caucasian) & $8(57.1)$ & $11(84.6)$ & 0.11 \\
\hline Age (mean years) & 65.8 & 64.0 & 0.65 \\
\hline Duration of disease (mos) & 39.5 & 23.6 & 0.29 \\
\hline Mean BCVA in ETDRS letters (Snellen) & $15.4(20 / 125)$ & $18.3(20 / 125)$ & 0.44 \\
\hline Mean FTH $(\mu \mathrm{m})$ & 481.4 & 512.9 & 0.84 \\
\hline Patients belonging to original READ-2 ranibizumab group $(\%)^{\mathrm{a}}$ & $7(50)$ & $1(7)$ & 0.03 \\
\hline Patients belonging to original READ-2 laser group (\%) & $5(36)$ & $5(39)$ & 1.0 \\
\hline Patients belonging to original READ-2 ranibizumab + laser $(\%)^{\mathrm{a}}$ & $2(14)$ & $7(54)$ & 0.04 \\
\hline \multicolumn{4}{|c|}{ Visual acuity (in ETDRS letters), anatomic outcomes (in $\mu m$ ) and treatment history } \\
\hline VA M24 & $15.8(20 / 125)$ & $12.4(20 / 160)$ & 0.14 \\
\hline Delta VA M24 & 0.4 & -5.9 & 0.23 \\
\hline Peak VA during 24 mos & $30.4(20 / 63)$ & $26.4(20 / 80)$ & 0.10 \\
\hline Delta VA peak & 15.0 & 8.1 & 0.35 \\
\hline time from baseline to peak VA & 10.2 & 13.6 & 0.2 \\
\hline Mean number of RBZ injections over $24 \operatorname{mos}^{\mathrm{a}}$ & 9.2 & 4.3 & $<0.001$ \\
\hline Mean number of focal laser treatments before and during the study & 2.5 & 3.4 & 0.29 \\
\hline FTH M24 & 450.3 & 292.2 & 0.004 \\
\hline \multicolumn{4}{|c|}{ Percentage frequencies of characteristics identified on fluorescein angiogram $(\mathrm{n} / \mathrm{n}$ graded $)$} \\
\hline Extensive laser & $46(6 / 13)$ & $73(8 / 11)$ & 0.24 \\
\hline Pigmentary changes in fovea & $58(7 / 12)$ & $82(9 / 11)$ & 0.37 \\
\hline Foveal atrophy & $43(3 / 7)$ & $80(8 / 10)$ & 0.16 \\
\hline Definite macular ischemia & $33(3 / 9)$ & $10(1 / 10)$ & 0.30 \\
\hline Laser in central $1 \mathrm{~mm}^{\mathrm{a}}$ & $23(3 / 13)$ & $78(7 / 9)$ & 0.03 \\
\hline
\end{tabular}

Abbreviations: BCVA/VA, best-corrected visual acuity; BL, baseline; FTH, foveal thickness; M, month; mos, months.

a Significant with $P<0.05$.

the presence or absence of residual edema. However, a limitation of our study is that it was a retrospective analysis of a clinical trial and may not have had sufficient power to detect all differences between groups that contribute to poor visual outcome. Therefore, we cannot conclude that our failure to identify differences in some of the parameters, such as severe macular ischemia, conclusively proves that they do not exist. Surprisingly, seven patients with a good visual outcome $(\geq 20 / 40)$ were judged to have severe macular ischemia because of widespread closure of perifoveal capillaries involving $360^{\circ}$ of capillaries bordering the foveal avascular zone. This could mean that macular ischemia does not contribute to poor visual outcome in patients with DME, or it may mean that closure of perifoveal capillaries is not a valid indicator of macular ischemia and that some patients may obtain sufficient oxygenation from the choroid to maintain foveal function. Thus, we conclude that dropout of perifoveal capillaries for $360^{\circ}$ for at least $1 \mathrm{~mm}$ around the fovea is not strongly associated with a poor visual outcome, but as we do not know how well this anatomic finding correlates with macular ischemia, we cannot determine whether macular ischemia contributes to poor outcome. One might expect that patients with extensive macular laser are more likely to have had foveal damage or may have exceeded a threshold of loss of central retinal tissue that would lead to reduced vision. However, there was no association between patients with extensive macular laser photocoagulation and reduced visual outcome, which is consistent with results of a previous study. ${ }^{12}$ Closeness of photocoagulation burns to the fovea may be more important than total amount of macular laser. The percentage of patients with laser burns in the central $1 \mathrm{~mm}$ was significantly greater in patients with a poor visual outcome and no residual edema compared with patients who had a poor visual outcome due to residual edema. This raises the possibility that laser photocoagulation in close proximity to the fovea could contribute to poor visual outcome in patients treated with a combination of an anti-VEGF agent and focal laser, and it may be prudent to avoid it since we no longer have to rely solely on laser.

In conclusion, after 2 years of treatment of DME with RBZ no more frequently than every 2 months for recurrent edema, about $27 \%$ of patients have a poor 
visual outcome (BCVA $\leq 20 / 100)$, with about half having some residual edema that could be contributing. More aggressive follow up and treatment with RBZ was able to improve vision in some of these patients. ${ }^{9}$ Foveal atrophy was substantially more common in patients with poor visual outcome than in patients with a better visual outcome suggesting that photoreceptor damage was an important contributor to reduced vision. Severity and/or chronicity of edema may have contributed because poor vision at baseline correlated with a poor visual outcome and, although many patients with poor vision at baseline showed substantial improvement from baseline BCVA at some point in the trial, this improvement was gradually lost. Focal laser within $1 \mathrm{~mm}$ of the center of the fovea was a significant factor associated with poor vision in patients who did not have persistent edema as a cause of poor vision. These data suggest that treatment with anti-VEGF agents should be initiated early in the disease process before vision is substantially reduced. Focal laser therapy is welltolerated in most patients, but in view of the substantial efficacy of anti-VEGF agents, it is prudent to avoid laser photocoagulation in close proximity to the fovea.

\section{Contributors}

\section{The READ-2 Study Group}

\section{Clinical Sites}

Black Hills Regional Eye Institute:

Principal Investigator: Prema Abraham, MD

Coordinator: Buffi Green, Kristi Livermont

\section{East Bay Retina Consultants}

Principal Investigator: Eugene S Lit, MD Investigators: Daniel A Brinton, MD, Scott S Lee, MD Coordinator: Scotty Renslow

\section{Eye Care Specialists}

Principal Investigator: Erik F Kruger, MD Coordinator: Patty Yuhas, COA

\section{Illinois Retina Associates}

Principal Investigator: John S Pollack, MD

Investigators: Joseph M. Civantos, MD

Coordinator: Barbara J Ciscato

\section{Johns Hopkins University/Wilmer Eye Institute}

Principal Investigator: Diana V Do, MD Investigators: Peter Campochiaro, MD, Daniel Finkelstein, MD, Morton F Goldberg, MD, James T Handa, MD, Quan Dong Nguyen, MD, MSc,
Jennifer U Sung, MD, Howard Ying, MD, PhD,

Ingrid Zimmer-Galler, MD

Coordinators: Gulnar Hafiz, MD, MPH, Lisa Azzaro, COT, Lisa Greer, COT, MBA, Ovais Shaikh, MD, COT, Jennifer Simmons, COT

\section{Midwest Eye Institute}

Principal Investigator: Thomas Ciulla, MD

Coordinator: Neelam Thukral

\section{Ophthalmic Consultants of Boston}

Principal Investigator: Jeffrey S Heier, MD Investigators: Janet J Chieh, MD, Tina S Cleary, MD, Gregory L Fenton, MD, David S Liao, MD, Trexler M Topping, MD, Torsten W Wiegand, MD, Grant P Janzen, MD, Sumit P Shah, MD, Jeffrey A Chang, MD

Coordinator: Lindsey Williams

\section{Retina Consultants of Arizona}

Principal Investigator: Pravin U Dugel, MD Investigators: Jack Sipperley, MD, Donald W Park, MD, Judy Liu, MD, Derek Y Kunimoto, MD, Edward J Quinlan, MD, Arthur Mollen, DO, Jaime R Gaitan, MD Coordinator: Sarah G Mobley, CCRC

\section{Retina Consultants of Nevada-Las Vegas}

Principal Investigator: Allen Thach, MD Investigators: Roger Simon, MD, R Jeffrey Parker, MD, Rodney D Hollifield, MD, Roy H Loo, MD, MeherYepremyan, MD, Irene Voo, MD, Jason C Wickens, MD

Coordinators: Janet Seybert, Cassondra Major, Mia Davis, Christy Browder, Melissa Rediker

\section{Retina Institute of California}

Principal Investigator: Thomas S Chang, MD Investigators: Michael A Samuel, MD, Anthony J Culotta, MD, Ednan Ahmed, MD

Coordinator: Yvette Baghoomian, Coleman Ho

\section{Retina-Vitreous Associates Medical Group}

Principal Investigator: David Boyer, MD Investigators: Roger L Novack, $\mathrm{MD}, \mathrm{PhD}$, Thomas $\mathrm{G}$ $\mathrm{Chu}, \mathrm{MD}, \mathrm{PhD}$, Firas M Rahhal, MD, Janet Jill Hopkins, MD, FRCSC, HomayounTabandeh, MD, MS, FRCP, FRCS, FRCOphth, Richard H. Roe, MD, MHS Coordinator: Tammy Gasparyan, Janet Kurokouchi, Charles Yoon 


\section{University of New Mexico}

Principal Investigator: Arup Das, MD, PhD

Investigators: Mark Schluter, MD

Coordinator: Sheila Nemeth, COMT

\section{University of Southern California/Doheny Eye Institute}

Principal Investigator: Jennifer Lim, MD (year 1);

Dean Eliott, MD (years 2 and 3)

Coordinator: Margaret Padilla

\section{Steering Committee}

Peter A Campochiaro, MD

Jeffrey S Heier, MD

Quan Dong Nguyen, MD, MSc, Chair

\section{Data Safety and Monitoring Committee}

Brian P Conway, MD, University of Virginia

David Wilson, MD, Oregon Health and Science

University, Casey Eye Institute

\section{Reading Center}

The Retinal Imaging Research and Reading Center at Wilmer

Roomasa Channa, MD

Mohamed Ibrahim, MD

Yasir Sepah, MD

Syed Mahmood Shah, MBBS.

Data Collection and Monitoring Center, Wilmer Eye Institute, Johns Hopkins University

Afsheen Khwaja, MD

John Putzke, PhD, MSPH

Yasir Sepah, MD

\section{Coordinating Center, Wilmer Eye Institute, Johns Hopkins University}

Gulnar Hafiz, MD, MPH

Velma Pack, BA

\section{Statistical Analyses}

Raafay Sophie, MD

Afsheen Khwaja, MD

Roomasa Channa, MD

Yasir Sepah, MD

\section{Summary}

\section{What was known before:}

- Multiple studies have shown that anti-VEGF injections can be successfully used to treat DME.

- However, a proportion of patients continue to have poor visual outcome despite the treatment.

What this study adds:

- This study reports factors associated with poor visual outcomes in patients with DME treated with anti-VEGF therapy-residual macular edema accounted for poor vision in about half the patients.

- Foveal atrophy was more common among patients with poor visual outcome compared with those with better outcomes.

- In patients with resolved macular edema, laser scars within $1 \mathrm{~mm}$ of foveal center were associated with poor vision.

\section{Conflict of interest}

Afsheen Khwaja was an employee of JHU during the conduct of the study, but is now an employee of Santen Inc. Diana V Do has the following potential conflicts of interest: consultant for ISTA and Johns Hopkins University has received payment for her consulting with Regeneron and Genentech. She has received an honorarium from Heidelberg. Johns Hopkins University, the previous employer of Dr Do receives research support from Genentech, Regeneron, Heidelberg, and Pfizer. Quan Dong Nguyen has the following potential conflicts of interest: consultant for Bausch and Lomb, and Santen. The Johns Hopkins University receives payment for his consulting with Genentech, Acucela, Pfizer,

Regeneron, GlaxoSmithKline, and Heidelberg. Johns Hopkins University, the previous employer of Dr Nguyen, has received research support from Genentech, MacuSight, and Regeneron. Dr Nguyen chairs the Steering Committee for the RISE and RIDE studies. Peter A Campochiaro has the following potential conflicts of interest: consultant for Kala Pharmaceuticals and Applied Genetic Technologies Corporation and served as a consultant for Allergan within the past 2 years. Johns Hopkins University receives payment for his consultation with Genentech, Regeneron, and Aerpio. He receives research support from Genentech, Regeneron, Allergan, Aerpio, Genzyme, and Oxford BioMedica. These activities are being managed by the Conflict of Interest Committee of the Johns Hopkins University School of Medicine.

\section{Acknowledgements}

Jiangxia Wang, MS, MA, assisted with the data analysis for this study. She is affiliated with the Biostatistics 
Center, Department of Biostatistics, Johns Hopkins Bloomberg School of Public Health; supported by Wilmer Biostatistics Core Grant EY01765. The study was supported by Genentech and by a grant from the Juvenile Diabetes Research Foundation.

\section{References}

1 Klein R, Klein B. Vision disorders in diabetes. In: Group NDD editor, Diabetes in America, 2nd ed. National Institutes of Health: Washington, DC, USA, 1995, pp 293-330.

2 Nguyen QD, Tatlipinar S, Shah SM, Haller JA, Quinlan E, Sung J et al. Vascular endothelial growth factor is a critical stimulus for diabetic macular edema. Am J Ophthalmol 2006; 142: 961-969.

3 Nguyen QD, Shah SM, Heier JS, Do DV, Lim J, Boyer D et al. Primary end point (six months) results of the Ranibizumab for Edema of the mAcula in Diabetes (READ-2) Study. Ophthalmology 2009; 116: 2175-2181.

4 Nguyen QD, Shah SM, Khwaja AA, Channa R, Hatef E, Do DV et al. Two-year outcomes of the Ranibizumab for Edema of the mAcula in Diabetes (READ-2) study. Ophthalmology 2010; 117: 2146-2151.

5 The Diabetic Retinopathy Clinical Research Network. Randomized trial evaluating ranibzumab plus prompt or deferred laser or triamcinolone plus prompt laser for diabetic macular edema. Ophthalmolgy 2010; 117: 1064-1077.

6 Massin P, Bandello F, Hansen LL, Harding SP, Larsen M, Mitchell $\mathrm{P}$ et al. Safety and efficacy of ranibizumab in diabetic macular edema (RESOLVE Study). Diabetes Care 2010; 33: 2399-2405.

7 Mitchell P, Bandello F, Schmidt-Erfurth U, Lang GE, Masin P, Schlingemann RO et al. The RESTORE Study. Ranibizumab monotherapy or combined with laser $v$ s laser monotherapy for diabetic macular edema. Ophthalmology 2011; 118: 615-625.

8 Nguyen QD, Brown DM, Marcus DM, Boyer DS, Patel S, Feiner $\mathrm{L}$ et al. Ranibizumab for diabetic macular edema. Results from 2 Phase III Randomized Trials: RISE and RIDE. Ophthalmology 2012; 119: 789-801.

9 Do DV, Nguyen QD, Khwaja AA, Channa R, Sepah YJ, Sophie $\mathrm{R}$ et al. Ranibizumab for edema of the macula in diabetes study: 3-year outcomes and the need for prolonged frequent treatment. JAMA Ophthalmol 2013; 131(2): 139-145.

10 Chung EJ, Roh MI, Kwon OW, Koh HJ. Effects of macular ischemia on the outcome of intravitreal bevacizumab therapy for diabetic macular edema. Retina 2008; 28 : 957-963.

11 Jonas JB, Martus P, Degenring RF, Kreissing I, Akkoyun I. Predictive factors for visual acuity after intravitreal triamcinolone treatment for diabetic macular edema. Arch Ophthalmol 2005; 123: 1338-1343.

12 Aiello LP, Edwards AR, Beck RW, Bressler NM, Davis MD, Ferris $\mathrm{F}$ et al. Factors associated with improvement and worsening of visual acuity 2 years after focal/grid photocoagulation for diabetic macular edema. Ophthalmology 2010; 117: 946-953. 